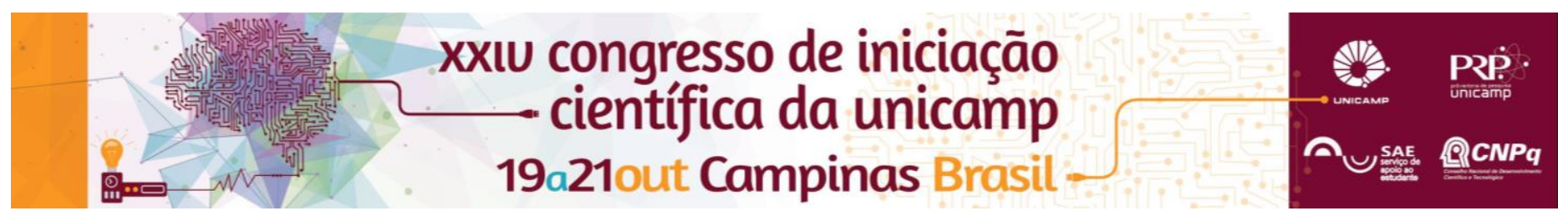

\title{
O SIGNIFICADO DE CUIDADOS PALIATIVOS PARA ENFERMEIROS (AS) EM UMA UNIDADE PEDIÁTRICA
}

\author{
Natália Dias dos Santos Cotrim, Ana Raquel Medeiros Beck.
}

\begin{abstract}
Resumo
Objetivos: Compreender qual o significado de Cuidados Paliativos para enfermeiros (as) de internação pediátrica. Identificar as possíveis dificuldades no cuidado desses pacientes. Perceber quais os sentimentos desses profissionais em relação a pacientes pediátricos em cuidados paliativos. Identificar se o profissional obteve algum preparo ou conhecimento do tema durante seu curso. Percurso Metodológico: Pesquisa qualitativa, foram entrevistados enfermeiros (as) de uma unidade de internação pediátrica com no mínimo dois anos de experiência que prestaram assistência a crianças em cuidados paliativos. Ao todo foram entrevistados dez enfermeiros, com o auxílio de um roteiro semiestruturado. Processamento e análise de dados: As entrevistas gravadas foram transcritas e submetidas à Análise de Conteúdo, segundo Bardin. Resultados e discussão: Da análise dos discursos resultaram seis categorias. As compreensões sobre cuidados paliativos resultaram em convergências e divergências, demonstrando deficít no ensino de enfermagem e uma falta de apoio psicológico a esses profissionais. Conclusões: Os enfermeiros necessitam de um conhecimento maior sobre o tema, além disso a instituição necessita investir na realização de cuidados paliativos adequados.
\end{abstract}

\section{Palavras-chave:}

Cuidados Paliativos, Enfermagem Pediátrica, Criança.

\section{Introdução}

As crianças assim como os mais velhos, conquistaram benefícios quando o assunto é a expansão tecnológica, contudo, essa expansão alterou o perfil das doenças nessas crianças, tornando cada vez mais frequente à assistência a crianças com doenças crônicas e ameaçadoras à vida. Por isso os cuidados paliativos devem envolver uma assistência ativa e integral à essas crianças, nas dimensões de seu corpo, mente e espírito, além de oferecer um bom suporte para a sua família ${ }^{1}$. Segundo a definição de cuidados paliativos "Não são cuidados de menor importância ou 'cuidados para pessoas que estão morrendo'. São cuidados que permitem que pessoas com doenças incuráveis, que ameaçam a continuidade da vida, vivam da maneira mais plena possível $^{2}$. Tendo em vista esses pressupostos pretendeuse nesta pesquisa compreender o significado de cuidados paliativos para os (as) enfermeiros (as) desses pacientes, por ser a categoria profissional que permanece na assistência direta a criança e sua família.

\section{Resultados e Discussão}

$\mathrm{Da}$ análise dos discursos resultaram seis categorias: Cuidados Paliativos (CP) como modo de conforto, na maioria das entrevistas é considerado uma maneira de amenizar a dor e sofrimento dos pacientes. CP como qualidade de vida, alguns compreendem como uma forma de proporcionar uma qualidade de vida. CP como cuidados gerais, um dos entrevistados conceituou como sendo todos os cuidados prestados em uma enfermaria a um paciente. CP como cuidado de pacientes fora de possibilidades terapêticas de cura, enfatizaram que os profissionais não deveriam cometer "atos heroicos", mas sim proporcionar cuidados aos pacientes para que consigam lidar melhor com a sua condição de saúde. CP como esperança, de que nem tudo está "perdido", revelando a fé e religião como suporte para enfrentar os problemas. Quando questionados sobre os conhecimentos sobre o tema percebeu-se um déficit no ensino da graduação de enfermagem sobre 0 assunto. Os enfermeiros com menos tempo de formação referiram pouca abordagem no curso e os mais antigos na profissão negaram 0 a abordagem deste conteúdo. Quanto à questão psicológica a grande maioria referiu falta de preparo e apoio psicológico por parte da instituição. Quanto a maneira que a enfermagem poderia prestar esses cuidados consideram importante a sintonia entre a equipe multiprofissional e o apoio a família, ressaltando a importância de um cuidado integral e humanizado. A reafirmação dos princípios dos Cuidados Paliativos, através da informação adequada, constitui a melhor forma de transpor barreiras ainda existentes para a implantação de uma política de Cuidados Paliativos efetiva ${ }^{3}$.

\section{Conclusões}

Os conceitos de cuidados paliativos não são muito claros para os alguns enfermeiros que não tiveram contato ou não se atualizaram. Os enfermeiros que ao término da graduação fizeram alguma especialização ou pós-graduação, possuem uma definição mais adequada e recente sobre Cuidados Paliativos (CP). Existe uma necessidade de maior divulgação, pesquisas $e$ conhecimentos sobre o tema entre a equipe multidisciplinar, visando a melhora da assistência à criança em cuidados paliativos e sua família.

\section{Agradecimentos}

Agradeço a minha orientadora Ana Raquel Medeiros Beck pela oportunidade e ao PIBIC/CNPQ.

\footnotetext{
Referências:

1- Valadares MTM, Mota JAC, Oliveira BM. Cuidados paliativos em pediatria: uma revisão. Rev. Bioét. 2013. 21(3): 486-493.

2- Figueiredo F. Academia Nacional de Cuidados Paliativos (ANCP). Website. "Vamos falar de Cuidados Paliativos?". 2015. Disponível em: http://www.paliativo.org.br/noticias/2015/05/.

3- Maciel, MGS et al. Coordenação Institucional de Reinaldo Ayer de Oliveira. Cuidado Paliativo. Cad. CREMESP. São Paulo: Conselho Regional de Medicina do Estado de São Paulo, 2008 p.17.
} 